\title{
MUESTRAS DEL LÉXICO EN TORNO A LA SEDA EN UN TRATADO DEL SIGLO XVI ${ }^{1}$
}

\author{
Pedro Mármol Ávila \\ Universidad Autónoma de Madrid/Université de Genève \\ pedro.marmol@uam.es
}

Resumen: En este trabajo se analizan ocho voces extraídas del Arte para criar seda (1581), de Gonzalo de las Casas, las cuales se encuentran estrechamente ligadas, en un sentido semántico, a dicha fibra natural. Se profundiza en el origen de estas, su significado y su proyección en la historia de la lengua española, para lo cual se complementan los contextos de uso del tratado con otros externos, cercanos y lejanos en el tiempo, así como se recurre a datos relativos a su presencia en los diccionarios del español.

Palabras clave: Gonzalo de las Casas, Arte para criar seda, léxico, sericicultura, semántica.
Title: Examples of silk vocabulary in a 16th century treatise.

Abstract: This paper focuses on eight words taken from the Arte para criar seda (1581), by Gonzalo de las Casas. They are closely linked to silk in a semantic sense. We study their origins, their meanings, and their projections in the history of the Spanish language. For that purpose, the contexts of use of the treatise are complemented with some other external contexts of use, close and distant in time. Also, we consider their presence in Spanish dictionaries.

Keywords: Gonzalo de las Casas, Arte para criar seda, lexicon, sericulture, semantics.

\section{INTRODUCCIÓN}

Pese a los importantes avances logrados en los últimos tiempos en el estudio del léxico científico o técnico de los siglos XVI y XVII (ver, por ejemplo, Verdonk y Mancho Duque, 2010; Quirós García, 2017; Jiménez Ríos, 2018), este terreno permanece abierto a nuevas aportaciones. Estas, entre otras cosas, permitirán ampliar el conocimiento que tenemos de la conformación de un vocabulario que se proyectará

1 Este trabajo forma parte de los resultados del proyecto de investigación «La conformación del tecnolecto geopónico. Siglo XVI» (PID2019-103898GB-I00), financiado por el Ministerio de Ciencia e Innovación. Asimismo, se ha llevado a cabo gracias al programa de Ayudas para la Formación de Profesorado Universitario (FPU15/05737), del Ministerio de Educación, Cultura y Deporte. 
en la historia de la lengua española y hasta el día de hoy, en un proceso con características comunes, pero a la vez singular según la voz o el grupo de voces examinados (Gutiérrez Rodilla, 1998: 59-81).

En consecuencia, cabe ocuparse de un conjunto léxico delimitado de acuerdo con su semántica, el sericícola, es decir, el referente a la 'fabricación y producción de la seda' (DLE: s. v. sericicultura), una noción válida, mutatis mutandis, para la misma actividad a la altura del siglo XVI. Los medios y los procesos han cambiado, conforme a avances técnicos de diversa índole ${ }^{2}$, pero el fin de lograr la máxima eficiencia en la obtención de esta fibra natural se mantiene vigente. En particular, esta contribución profundiza en una serie de voces extraídas del Arte para criar seda (1581), de Gonzalo de las Casas, impreso en su editio princeps en Granada por René Rabut y al cual se le ha dedicado insuficiente atención hasta el presente ${ }^{3}$. Se erige en el primer tratado consagrado exclusivamente a la seda en español, y constituye mi «objeto de estudio» aquí, en los términos de Coseriu:

[...] un discurso determinado (texto) puede considerarse en sí mismo como objeto de estudio (y de interpretación); y, en tal caso, habrá que examinar, naturalmente, todas las determinaciones y todas las relaciones contextuales de las «palabras», sin olvidar las asociaciones de todo tipo que funcionan en el texto estudiado (1981: 125).

Priorizo, así pues, un texto concreto y el léxico que posee, lo cual me encauza hacia la historia de la lengua española, a fin de explorar un total de ocho voces desde una perspectiva diacrónica. Lo haré deteniéndome en cada una de ellas, lo cual justifica que la lista no se amplíe, aunque sería sencillo hacerlo - por ejemplo, con otros vocablos presentes en los fragmentos del Arte para criar seda citados a lo largo de este estudio-. La selección converge en el campo semántico que, dentro del tratado, se establece en torno a la seda, y que, a su vez, ofrece una cierta variedad dentro de su unidad. Ahondaré, para ser exactos, en cinco estratos de significado: los orígenes de

\footnotetext{
2 Pueden leerse diversos abordajes de la historia de la seda y los factores, incluidos los técnicos, que han influido en su cultivo en España y Portugal en Comisión Española de la Ruta de la Seda (1996) y Franch Benavent y Navarro Espinach (2017).

3 De los pocos acercamientos a De las Casas y su tratado, puedo destacar González Obregón (1903), Comisión Española de la Ruta de la Seda (1996), Garrido Aranda (1996), Valiente Romero (2010) o Mármol Ávila (2020), a los que cabe agregar las alusiones de González Sopeña (2019). Es pertinente atender también a Carrillo Cázares (2003: 67-70), donde se descarta la autoría de Gonzalo de las Casas para la Guerra de los chichimecas, texto que se le ha atribuido.
} 
la seda $\left(\right.$ semilla $\left.a^{4}\right)$, la propia seda, ciertos tipos de esta (atanquia, joyante y redondo), procesos que la involucran (bilar) y formas que puede adoptar (capillejo y madexa).

En total, cinco sustantivos - atanquia, capillejo, madexa, seda y semilla-, dos adjetivos - joyante y redondo- y un verbo - hilar-, de los cuales selecciono un contexto de uso de cada uno dentro del tratado. Para ello, me fundamento en la ayuda que cada contexto ofrece para discernir la semántica de estas voces ${ }^{5}$, lo cual me lleva a repetir alguno de ellos. Así, la aportación se cimienta sobre manifestaciones lingüísticas documentadas, noción que me conduce a ampliar los contextos del Arte para criar seda a partir de corpus y otras fuentes, con el propósito de conformar una base para el estudio de las ocho unidades léxicas. Los resultados quedarán reflejados, principalmente, en las sucesivas tablas del siguiente apartado, una por cada vocablo, que se rigen por unos criterios que es preciso explicitar ahora junto a otros referentes a la selección:

- Abordaré las ocho voces por orden alfabético, no según el lugar de aparición en el Arte para criar seda, aludiendo a ellas como como lemas. Esto me llevará a diversas formas flexionadas.

- Mostraré los contextos de uso del tratado de manera amplia, por el apoyo que esto supone para el análisis semántico que me propongo.

- Para los contextos de uso externos o complementarios al tratado, recurro primero a corpus. Los resultados recogidos provienen del CORDE y, en menor medida, del $C D H$, que cito tal como se presentan, lo mismo que pasa con la información sobre las ocurrencias ${ }^{6}$.

- Para seleccionar las ocurrencias de los corpus y listarlas, se impone el orden cronológico que estos establecen.

- De los resultados generados en los corpus, obvio las ocurrencias procedentes de repertorios lexicográficos, dado que de ellos me encargaré de modo específico a través de los ejemplos esparcidos a lo largo de todo el trabajo.

\footnotetext{
4 Menciono los vocablos, como cualquier extracto del Arte para criar seda, según las pautas para la presentación crítica de la Red Internacional CHARTA (Corpus Hispánico y Americano en la Red: Textos Antiguos): <https://www.redcharta.es/criterios-de-edicion/> [04/06/2020]. ción alguna.

Excepto con joyante y capillejo, que solo figuran una vez, con lo cual no hay que hacer selec-

6 Por ello, habrá que tomar con cuidado las fechas proporcionadas, relativas a obras que se conservan en testimonios posteriores a su composición, con lo cual, como es bien sabido, ciertas peculiaridades lingüísticas pueden no remontarse al original. El asunto reviste especial complejidad, respecto a los ejemplos que siguen, en los extractos de procedencia medieval, como pueden ejemplificar el Auto de los Reyes Magos o el Libro de buen amor.
} 
- Cuando los corpus arrojen datos poco consistentes a los presentes efectos, como primeras documentaciones de palabras que ya siglos antes se registran en el tratado de De las Casas y en diccionarios, pondré ejemplos de fuentes anexas. Los citaré con las grafías de la referencia consultada, como ocurre con los corpus, de igual modo que reproduciré la información relativa a estos contextos tal como se muestra. Además, cuando uno de estos manifieste, respecto a la misma voz, varias ocurrencias, será práctica habitual ofrecerlo ampliado para tener en cuenta dos de estas al menos, principio que se hace extensivo a los extractos del Arte para criar seda.

- En cuanto a los contextos complementarios al tratado, se distinguen los testimonios tempranos del vocablo y los testimonios tempranos del vocablo con sentido afín al uso del Arte para criar seda —en ambas vertientes, los más tempranos que he localizado-, siempre elegidos si su semántica arroja cierta claridad para situarlos en uno de esos dos apartados, evitando los homónimos o las ocurrencias que admiten dudas de serlo. Serán dos los ejemplos en cada una de las dos secciones, excepto cuando las documentaciones más tempranas contengan propiedades semánticas afines al uso del tratado, supuesto en el cual se citarán dos ejemplos en total. Habrá, también, casos en que el primer o el segundo uso de los no afines, dentro del corpus, esté precedido o seguido en el tiempo por uno afín, supuesto en el cual se mantiene la dinámica general: dos ocurrencias de cada uno.

Desde estas premisas, es posible hacer algunas calas en las soluciones léxicas de De las Casas, cuando carece de una tradición de tratados sericícolas en español en que inspirarse ${ }^{7}$, $\mathrm{r}$ rastrear la trayectoria de estas en la misma lengua.

\section{ACERCAMIENTO A LAS VOCES ELEGIDAS}

Procedo al análisis de cada una de las ocho voces anunciadas, haciendo hincapié en su origen, su significado y su proyección en la historia del español. 


\subsection{Atanquía}

\section{Contexto DE USO DEL TRATAdo}

$\ll[\ldots]$ siempre se á de procurar que la seda vaya limpia. La cual limpieça consiste en dos maneras: la primera, de mota y atanquía, y la segunda, del agua en que se á de hilar. Para quitar el atanquía se á de hazer en la mano, cuando sacan la hebra de los capullos, cortando todo lo gruesso que fuere atanquía antes que se pegue la tal hebra, porque si se quita después en el torno llévase a bueltas la seda fina con que se pegó. Y d'esta manera se aventaja seda a los que la an de quitar el atanquía, quitándola primero que se pegue» (Casas, 1581: 74r).

\begin{tabular}{|c|c|}
\hline $\begin{array}{l}\text { TESTIMONIOS TEMPRANOS DEL } \\
\text { VOCABLO }\end{array}$ & $\begin{array}{l}\text { TESTIMONIOS TEMPRANOS DEL VOCABLO } \\
\text { CON SENTIDO AFÍN AL USO DEL TRATADO }\end{array}$ \\
\hline $\begin{array}{l}\text { «Señora, por fijo o fija / en vos querría aver, / } \\
\text { más vos querría foder / que ser señor de Torija. } \\
\text { / Si meades por vedija, / fazédmelo entender, / } \\
\text { que yo vos faré poner / atanquía en la verija » } \\
\text { (1379-a. } 1425 \text {, Villasandino, Alfonso de: Poe- } \\
\text { sías [Cancionero de Baena]; CORDE })^{8} \text {. } \\
\text { «Y como la Lozana no es estada buena jamás de } \\
\text { su mal, el pelador no tenía harta atanquía, que } \\
\text { todo era calcina }(1528, \text { Delicado, Francisco: } \\
\text { La Lozana Andaluza; CORDE })^{9} \text {. }\end{array}$ & 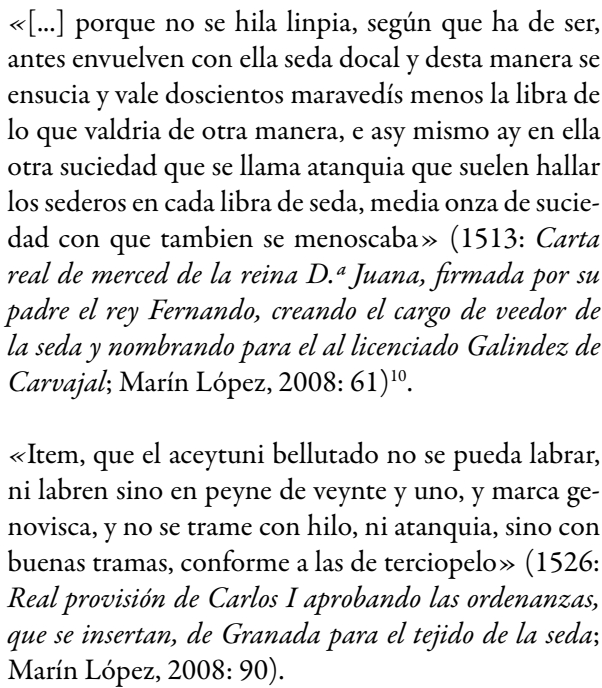 \\
\hline
\end{tabular}

Tabla 1. Un contexto de uso de atanquía en el Arte para criar seda y contextos de uso complementarios

8 Esta ocurrencia ha merecido un acercamiento reciente de López Quero (2010: 573).

9 Además, se registra una peculiar concordancia anterior a las dos: «Rio cabdal guadalhyar con todas las otras aguas de que te tu muy bien seruies salido es de madre et ua onon deuie. Ceuaquit açafia alladi quitir que tantafa antabuha quet araiarat megandara huo en notan atanquia» (1270-1284, Alfonso $\mathrm{X}$ : Estoria de España, II; CORDE). La razón reside en que «En el capítulo 909 [...] de la Crónica se trascribe una elegía a Valencia compuesta por Al-Uacaxí, de la cual se ofrece el texto primeramente y luego la traducción castellana. Pero el texto árabe ofrecido no es el original de la elegía, sino una mera retraducción macarrónica del texto castellano, hecha por quien no sabía hablar árabe» (PCG: LXII). Es esta la documentación más temprana del término a la que he accedido, como González Sopeña (2019: 224).

10 Este ejemplo y el siguiente son nombrados por González Sopeña (2019: 223-225) para la misma voz. 
Es relevante que el DHLE (s. v. atanquía), al ilustrar esta misma voz, muestre idéntico pasaje del Arte para criar seda, si bien lo segmenta en dos enunciados: el primero corresponde al final de nuestro fragmento y el segundo, al comienzo ${ }^{11}$. Cabe atribuir esta citación a la nitidez expositiva del tratado y a su temprana datación, elocuentes de la semántica de la palabra en la historia del español. En particular, De las Casas, en las líneas incluidas en la Tab. 1, recomienda intervenir sobre la atanquía y la mota ${ }^{12}$ para «que la seda vaya limpia», junto al lavado con agua, que «da mucho lustre a la seda y la haze que tenga gentil vista» (Casas, 1581: 74v). En cuanto a la atanquía: «[...] se á de hazer en la mano, cuando [los gusanos] sacan la hebra de los capullos, cortando todo lo gruesso que fuere atanquía antes que se pegue la tal hebra». O sea, debe separarse manualmente de la seda estándar de los capullos, en razón de su menor calidad, y, de no hacerse en el momento que se estipula, el proceso de la producción sericícola se verá perjudicado, quedando deteriorada la calidad del resultado final si no se hace más tarde.

El sentido del término en la órbita de la seda, en vista del tratado y los contextos externos aludidos, se manejaba ya a la altura del siglo XVI, y dejó de utilizarse, como la voz en cualquier otra vertiente semántica, tiempo después ${ }^{13}$, según sugiere la marca desus. junto a sus acepciones en el $D L E$ (s. v. atanquía): 'ungüento depilatorio, ordinariamente compuesto de cal viva, aceite y otras cosas', 'adúcar (\| seda exterior del capullo de seda)' y 'cadarzo (\| seda basta de los capullos)'. Habida cuenta de la segunda y la tercera, y en particular del valor que acotan para cadarzo y adúcar, sería fácil llegar a la conclusión, precipitada, de que atanquía significa en el contexto de De las Casas solo lo que hoy sería cadarzo ${ }^{14}$ : 'seda basta de los capullos enredados, que no se hila a torno' (DLE: s. v. cadarzo). Ahora bien, adúcar en el mismo diccionario posee una acepción compatible con atanquía tal como la emplea De las Casas: 'seda que rodea exteriormente el capullo del gusano de seda, y la cual siempre es más basta' (DLE: s. v. adúcar). En suma, quitar la seda de mala cali-

11 Con puntuación discutible en su segundo ejemplo, pues se reúne en una misma oración lo que, a mi juicio, es el final de una y el comienzo de otra: «[...] se ha de hilar para quitar el atanquía» (DHLE: s. v. atanquia).

12 Vocablo que denota otras imperfecciones de la seda, y no solo: 'son ciertos cadillos o nudillos que han quedado en el paño cuando le sacan del telar' (Covarrubias, 1611: s. v. motas). Destaca el número plural en la definición, como en Rosal (1601-1611: s. v. mota) cuando subraya el sentido de la voz en relación con la seda. Cito a Covarrubias (1611) y Rosal (1601-1611) por la edición de los diccionarios accesible en el NTLLE.

13 Lo sigo hallando en el siglo xIx: «El gusano de seda forma al principio una tela floja y rala, llamada borra o atanquía. Después trabaja otra más fina y tupida de que forma una casilla de seda, toda compuesta de hilos delgados fáciles de hilar» (Dubroca, 1826: 74).

14 O el caharzo en Murcia, como documentó Muñoz Garrigós (1979: 31). 
dad del capullo no excluye quitar la de mala calidad que lo rodea, con lo cual tienen lugar unas interesantes interferencias entre los vocablos, y la existencia de adúcar y cadarzo ha sido una de las razones por las cuales atanquia ha venido perdiendo vigencia, al compartir rasgos semánticos.

Al lado de ello, el sentido más sencillo de documentar en la historia del español de atanquía no tiene que ver, en principio, con la seda, sino con cierto ungüento depilatorio. Este es descrito en la primera de las tres acepciones anteriores del $D L E$ (s. v. atanquia), y tiene una sugestiva etimología: según el DAVAI (s. v. atanquia [cs.] y tanquia $[p t].)^{15}$, procede del andalusí attanqíya y este del árabe clásico tanqiyah 'limpieza, purificación ${ }^{16}$. Por tanto, la voz se ubica de modo mayoritario, y en un primer momento, en el ámbito de los cosméticos femeninos, cuyas denominaciones en la lengua española están en deuda con el mundo árabe (Barceló y Labarta, 2001: 3940). El uso es ejemplificado en los contextos de la Tab. 1 externos al tratado, los cuales permiten atestiguar la voz entre finales del siglo XIV y comienzos del XV. Además, indagan en este sentido Covarrubias (1611: s. v. atanquía) - 'cierta goma o betún o ungüento que hecho empasto, y puesto sobre el cuero, arranca los pelos'- y repertorios lexicográficos posteriores: Aut. (s. v. atanquia) ${ }^{17}$, Salvá (1846: s. v. atanquia), Alemany y Bolufer (1917: s. v. atanquía $)^{18}$ o el propio $D L E$, como ya he indicado.

Con relación a la última línea semántica, es preciso traer a colación indicios que llevan en otra dirección dentro del mundo de los cosméticos femeninos, a partir de un par de definiciones: 'pincettes à arracher le poil' (Oudin, 1607: s. v. atanquía para arrancar pelos) ${ }^{19} \mathrm{y}$ 'son las tenazuelas para quitar las cejas' (Rosal, 1601-1611: s. v. atanquia). Sirve la voz, según esto, para denotar otro útil depilatorio ${ }^{20}$. Ahora bien, con el tiempo, atanquía queda en un segundo plano en favor de nuevos procedimientos y herramientas que conciernen a los cosméticos femeninos, lo cual explica, junto a la pujanza de expresiones de semántica afín (depilatorio, pasta depilatoria, crema depilatoria, pinzas, tenacillas, etc.), su falta de actualidad en esta dimensión.

15 También el DECH (s. v. atanquía) la explica.

16 En algunos diccionarios se registra, junto a otras variantes, tanquía, como puede ejemplificar Salvá (1846: s. v. tanquía): 'ungüento o pomada para hacer caer el pelo' (cito este diccionario por la edición accesible en el NTLLE). Sin embargo, fuera de ciertas obras lexicográficas, no he conseguido documentar esta otra solución. En portugués, como señala el DAVAI (s. v. atanquía [cs.] y tanquia [pt.]), existe tanquia.

17 Cito $A u t$. por la edición del diccionario accesible en el NTLLE.

18 Cito a Alemany y Bolufer (1917) por la edición del diccionario accesible en el NTLLE.

19 Cito a Oudin (1607) por la edición del diccionario accesible en el NTLLE.

20 Nada se dice de esta otra vertiente de significado en Maíllo Salgado (1998: 286), el DAVAI (s. v. atanquia [cs.] y tanquia [pt.]), Serrano-Niza (2007: 561-562) o González Sopeña (2019: 223-225). Requeriría de estudio específico y parece complicada de documentar más allá de los diccionarios. 
En fin, resulta evidente la preeminencia de la vertiente de la cosmética en los significados del término otorgados por los diccionarios de los siglos XVI y XVII, siendo Franciosini (1620: s. v. atanquia $)^{21}$ una excepción, al hacer hincapié en esta y en la sericícola - una sorte d'unguento per sbarbar i capelli, o vero filaticcio ${ }^{22}$ crudo'-, que se consolida con el primer diccionario académico: 'se llama también la estopa de la seda, que otros llaman cadarzo' (Aut.: s. v. atanquía). La circunstancia, con la etimología y los contextos inicialmente más comunes, trasluce un valor primero de atanquía en el español unido a la cosmética que, gracias a un proceso metafórico y metonímico, se especializó en la seda: se asocia el vello con la seda y se produce una sustitución de la atanquía por la entidad sobre la que actúa, que pasa a denominarse como esta ${ }^{23}$.

\subsection{Capillejo}

\section{Contexto de uso del tratado}

«La manera de hilar esta seda se divide en dos o tres maneras: en redonda o joyante, que la una es gorda y la otra delgada, y la delgada buena para aparejos. $Y$ en esta ay otras diferencias conforme al gordor o delgadez d'ella, porque una será buena para telas, otra para tramas, otra para pelos. Y en la gorda no ay diferencia ninguna, porque d'ella se haze el capillejo, que es la seda torcida o floxos» (Casas, 1581: 73v).

\begin{tabular}{|c|c|}
\hline $\begin{array}{l}\text { TESTIMONIOS TEMPRANOS DEL } \\
\text { VOCABLO }\end{array}$ & $\begin{array}{c}\text { TESTIMONIOS TEMPRANOS DEL } \\
\text { VOCABLO CON SENTIDO AFÍN AL USO } \\
\text { DEL TRATADO }\end{array}$ \\
\hline $\begin{array}{l}\text { «[...] encontro vna donçella en vn muy fermoso } \\
\text { palafren que hera toda cana e lleuaua los cauellos } \\
\text { tendidos porlas espaldas como si fuese muy moça e } \\
\text { traia vn capillejo de Rosas enla cabeça» (ca. 1414, } \\
\text { anónimo: traducción de Lanzarote del Lago; } \\
\text { CORDE). }\end{array}$ & $\begin{array}{l}\text { «Tres carruseres el uno de Valençia mucho bueno } \\
\text { y los otros labrados con oro y el otro de capillejo } \\
\text { de seda y blanca» (1478: Inventario de los bienes } \\
\text { del conde de Plasencia; Lora Serrano, 1991: 328). }\end{array}$ \\
\hline
\end{tabular}

21 Cito a Franciosini (1620) por la edición del diccionario accesible en el NTLLE.

22 La voz filaticcio, que puede ser ininteligible para el hablante actual de italiano, es explicada por Cormon y Manni (1821: s. v. capullo): 'seda de capullos'. Filaticcio crudo alude a la seda de capullo sin procesar, a la espera de su tratamiento, lo que entronca, más o menos, con el sentido de atanquía.

23 Planteamiento semejante en el DAVAI (s. v. atanquia [cs.] y tanquia [pt.]), retomado en González Sopeña (2019: 224). 
$\ll[\ldots]$ vi a su madre vender toquillas e capillejos: muchas vezes vino a mi casa diziéndome sy quería conprar alvaneguillas la vieja de su madre» (1438, Martínez de Toledo, Alfonso: Arcipreste de Talavera [Corbacho]; $\mathrm{CDH}$ ). $\ll[\ldots]$ por manera que el maestro que tuviere toquería y capillejo no use terciopelo; y el que tuviere terciopelo no use toquería, ni capillejo, ni menos pueda ponello nuevamente» (1573: Ordenanzas de Felipe II para los torcedores de seda de Toledo; Salvá y Sainz de Baranda, 1849: 382).

Tabla 2. Un contexto de uso de capillejo en el Arte para criar seda y contextos de uso complementarios

El nuevo fragmento del Arte para criar seda también funciona a título ilustrativo dentro del DHLE (s. v. capillejo $)^{24}$, que arroja una definición interesante de la voz que me ocupa: 'madeja de seda, doblada y torcida en disposición de usarla para coser', la cual coincide, palabra por palabra, con la primera que ofrece el $D L E$ (s. v capillejo). Esta converge con el tratado cuando este precisa que, con la seda «gorda », «se haze el capillejo, que es la seda torcida o floxos ${ }^{25}$, por la alusión a la seda como materia que lo constituye, de manera que el capillejo se asimilaría a la madeja en su forma, pero se diferencia en su restricción a la seda, como sugieren las fuentes referidas.

Sin embargo, la semántica más fácil de documentar tempranamente en la lengua española, al igual que con atanquía, no pertenece al campo de la seda, y se observa en los diccionarios de nuestros días: 'especie de cofia que se usaba antiguamente' (DLE: s. v. capillejo). Un valor ya vigente en el siglo $\mathrm{XV}$, a tenor de los ejemplos de la Tab. 2, pero la palabra debe rastrearse antes. Por la falta de un tratamiento por extenso en el DECH (s. v. capillo), es preciso acudir a Pottier (1981: s. $v$. capillo), que data el primer uso en 1389 , antecediendo en unas décadas a los primeros ejemplos que he aducido.

Antes de esas fechas, debió de circular el vocablo, del que, a modo de diminutivo, derivó capillejo: capillo, que forma parte del léxico patrimonial del español, al hundir sus raíces en el vocablo latino cAPPĚLLUS, como señala el $D E C H$ (s. v capillo). Este mismo diccionario sitúa su primer uso en el Poema de mio Cid (DECH: s. v. capillo), que es datado ca. 1140 (DECH: I, XLIII), en tanto que Pottier (1981: s.v. capillo) localiza el primero en 1252. Su sentido está explicado en Covarrubias

24 Que solo esgrime unas líneas: «En la [seda] gorda no ay diferencia ninguna, porque della se hace el capillejo, que es la seda torcida o floxos» (DHLE: s. v. capillejo).

25 No profundizo en seda torcida ni en floxos, dos vocablos cuyo sentido depende de la forma de la seda. Solo cabe apostillar que quedan relacionados en la definición que propone el $D L E$ (s. $v$. seda) para seda floja, que está ligada a los mentados floxos: 'seda lasa, sin torcer'. Aparte, del mismo contexto, más abajo me ocuparé de joyante, al cual De las Casas opone redonda, y ambos adjetivos son aplicados a la seda. 
(1611: s. v. capillo): 'el que ponen al rezién baptizado en la pila, en figura de la vestidura cándida de la gracia. Las labradoras de tierra de campos usan unos capillos que les sirven de sombreros y mantellinas, y las señoras de aquella tierra los traen por bizarrías de sedas de telas y de bordados. Capillo de fierro se toma por el capacete en lengua antigua. Esta definición, por su mención a los sombreros, nos pone en la estela de lo que era el capillejo, puesto que permite intuir el proceso semántico en virtud del cual unos de menor tamaño son denominados por este diminutivo, hasta adquirir unas propiedades caracterizadoras que lo alejan de derivados análogos formados con otros sufijos, es decir, hasta lexicalizarse, y, como tal, figurar en calidad de lema dentro de los diccionarios del español. Al cabo, designa una cofia de amplia difusión entre el público femenino en el siglo XIV y posteriores (Sousa Congosto, 2007: 107), en consonancia con el contenido de los ejemplos correspondientes de la Tab. 2. Por tanto, no sorprende que las acepciones de los primeros diccionarios del español remitan principalmente a la prenda, como bien ilustra Oudin (1607: s. v. capillejo de muger): 'une coiffe de femme faite de réseau, escoffion ${ }^{26}$.

Este sentido original de capillejo, por un proceso metafórico, acaba designando una entidad a la que se asemeja en la forma, que es la que se vincula con la actividad sedera. Para ilustrarlo pueden valer estos versos: «" ¿Manto de bermejo / hasle ya donado?" / "Y aun buen capillejo / de hilo trenado, / azul y morado, / nuestramo, / ya soy desposado" » (1481-1496, Encina, Juan del: Poesias [Cancionero]; CORDE). El adjetivo trenado - 'dispuesto en forma de redecilla, enrejado o trenza' (DLE: $s$. v. trenado) - conecta con el sentido que me interesa ahora de capillejo, toda vez que define la distribución del hilo.

En último lugar, la vigencia del término está en entredicho: su ausencia del $D E A$, unida a la dificultad que he tenido para documentarlo en testimonios recientes, así lo prueban. Comparte esta característica con atanquia, que en el caso de $c a-$ pillejo parece obedecer a dos motivos: la limitación en el tiempo de las prendas, con lo cual, junto al objeto, la voz o algunos de sus sentidos se suelen difuminar, y la capacidad de otra palabra - madeja - para aglutinar valores que, en principio, correspondían a capillejo, lo cual ha reducido la incidencia de esta última. No sorprende, por consiguiente, que se registre la construcción madeja de seda, o madexa de seda,

\footnotetext{
26 Dicho sea de paso, Oudin (1607), Franciosini (1620) y Salvá (1846) albergan el lema capellejo, pero lo definen de modo diferente con respecto a capillejo, siempre en torno al léxico de la vestimenta: mientras que Oudin (1607: s. v. capellejo) lo hace equivalente semántico de capillejo —al cual remite en la entrada-, Franciosini (1620) y Salvá (1846) distinguen entre uno ('scuffia o rete con che le donne tengono i capelli raccolti e uniti' [Franciosini, 1620: s. v. capillejo de muger] y 'especie de cofia' [Salvá, 1846: s. v. capillejo]) y otro ('rete che le donne portano in testa, cuffia' [Franciosini, 1620: s. v. capellejo] y 'cofia, redecilla' [Salvá, 1846: s. v. capellejo]).
} 
en la historia del español, como es fácil atestiguar en el propio siglo XVI: «Ocho madexas de seda amarilla e negra e roja, abrá tres honsas e media, docientos y treinta y ocho marauedis» (1538, anónimo: Escritura de inventario, tasación y partición de los bienes que quedaron por fin y muerte...; CORDE). Y durante los siglos posteriores, hasta la actualidad: «Tras visitar entusiasmado la ciudad en 1928 y el Santuario de nuestra Patrona, decidió emplear las madejas de seda de elaboración experimental que le cedieron los alumnos almerienses » (Valera Escobar, 2020).

\subsection{Hilar}

\begin{tabular}{|l|}
\hline \multicolumn{1}{|c|}{ CONTEXTO DE USO DEL TRATADO } \\
\hline $\begin{array}{l}\text { «No se á de hilar entre esta seda capullo ocal ni parche, porque estos dañan mucho la seda, sino después } \\
\text { por sí, o juntos los ocales y parches» (Casas, 1581: 74r-74v). }\end{array}$ \\
\hline \multicolumn{1}{|c|}{ TESTIMONIOS TEMPRANOS DEL VOCABLO (CON SENTIDO AFÍn AL USO DEL TRATADO) } \\
\hline «Qui borra filare, o en saial la metiere, o con cardas de fierro la cardare, pectet I morabeti al conceio» \\
(ca. 1234-1275, anónimo: Fuero de Cáceres; CORDE $)^{27}$. \\
«Del ueynteno grado del signo de tauro es la piedra quel dizen del algodon. Esta es fria \& seca de na- \\
tura. Blanca es de color, pero poco; assi que tira a color de cenisa clara. Et son falladas dellas grandes \& \\
pequennas. Liuiana es de peso, mas pero con tod esso; fuerte \& dura de quebrantar. \& quando la que- \\
brantan; fallan dentro en ella en manera dalgodon en sustancia \& en color. \& la uertud deste algodon \\
es atal que se non quema por fuego. \& filase \& fazen dello pannos como del otro algodon» (ca. 1250, \\
Alfonso X: Lapidario; CORDE) $)^{28}$.
\end{tabular}

Tabla 3. Un contexto de uso de hilar en el Arte para criar seda y contextos de uso complementarios

Los primeros usos que documento del verbo hilar conservan la $<\mathrm{f}$ - $>$ inicial latina. Circunstancia esperable, ya expliquemos la palabra por la vía etimológica, como proveniente de FILĀRE, ya lo hagamos por la vía de la derivación dentro de la misma lengua romance, pues las documentaciones tempranas de bilo también

27 No reproduzco la siguiente ocurrencia del corpus, en un sentido cronológico, dado que se trata de un pasaje equivalente, con cambios en las grafías (1242-1275, anónimo: Fuero de Usagre; CORDE).

28 Entre estas dos ocurrencias, en un sentido cronológico, he localizado otra: «Valió el buen conféssor, sanóla de la mano, / el braço que fo seco tornó verde e sano, / si pesado fo ante, depués fo bien liviano, / depués filó Semena sana a su solano» (ca. 1236, Berceo, Gonzalo de: Vida de Santo Domingo de Silos; CORDE). Sin embargo, como señala el DECH (s. v. hilo), «no es claro el sentido en Berceo, Duelo, $621 d$, y acaso se trate de otra palabra», motivo por el cual la he excluido de la Tab. 3. Dicho sea de paso, el DECH se refiere a la Vida de Santo Domingo de Silos y no, como dice, al Duelo de la Virgen. 
comienzan por $\left\langle\mathrm{f}->\right.$, al ser su étimo $\mathrm{FI} L \mathrm{UM}^{29}$. Son dos líneas de análisis complementarias (DECH: s. v. hilo).

El contexto del Arte para criar seda hace hincapié en no mezclar sedas de distintas calidades, a causa del perjuicio que ello supone para el hilo, tal como se advertía de la atanquia y ahora del capullo ocal y el parche $e^{30}$. Por tanto, hilar alude, en este caso, al tratamiento humano de la seda aglutinada en los capullos, siendo este un sentido característico que se da al verbo en el texto, pero el cual admite en la historia del español otro ligado a la consabida fibra natural. Ambos se deducen de unas elocuentes palabras de Covarrubias (1611: s. v. hilar): 'exercicio y ocupación de mugeres caseras y hazendosas. [...] Dicen que la araña nos enseñó el arte de hilar y de urdir telas. Ellas y los gusanos de seda desvavan el hilo de su vientre y se van consumiendo'. Es decir, la acción de hilar, o hacer hilos, puede corresponder al encargado de trabajar sobre los capullos, frecuentemente mujeres desde la Edad Media (García Herrero, 2008: 22-27):

«Maravíllome» dixo entonces riendo Gaspar Palavicino «que pues dais a las mujeres las letras, la continencia, la grandeza del ánimo y la templanza, no queráis también que ellas gobiernen las ciudades y hagan las leyes y traigan los exércitos y que los hombres se estén quedos hilando o en la cocina » (1534, Boscán, Juan: traducción de El cortesano de Baltasar de Castiglione; CORDE).

O al gusano que ha producido la seda:

[...] desde aquí a pocos años se criará más seda en esta Nueva España que en toda la cristiandad, porque se cría el gusano tan recio, que ni se muere porque le echen por ahí, ni porque le dejen de dar de comer dos ni tres días, ni porque haga los mayores truenos del mundo (que es lo que más daño les hace), ningun perjuicio sienten como en otras partes, que si truena al tiempo que el gusano hila, se queda muerto colgado del hilo (1536-1541, Motolinía [fray Toribio de Benavente]: Historia de los Indios de la Nueva España; CORDE).

Se trata de una doble vertiente significativa que mantiene vigencia, en concreto en las acepciones del $D L E$ (s. v. hilar) de 'reducir a hilo el lino, cáñamo, lana, seda,

29 Por ejemplo: «E deue ordir a $\mathrm{X}$ anieellos glomeros, et en el ordidura aya setenta et VIII cuerdas, et las cuerdas ayan çient filos. Tantos filos sean en la una pua del peyne, como en la otra. Texcan a quatro calças» (1218-ca. 1250, anónimo: Fuero de Zorita de los Canes; CORDE).

30 Una coaparición y un sustantivo interesantes que están presentes en el $D L E$ con semántica afín: explica la primera como 'capullo formado por dos o más gusanos de seda juntos' (s. v. capullo) y el segundo como 'cosa sobrepuesta a otra y como pegada, que desdice de la principal' (s. v. parche). La segunda definición, claro está, tiene un alcance mucho más general que la primera. 
algodón, etc.' y 'dicho de algunos insectos y de las arañas, y en especial del gusano de seda: Sacar de sí la hebra para formar el capullo o la tela'. Esta dualidad también se observa en hilo, en las acepciones actuales de 'hebra larga y delgada de una materia textil, especialmente la que se usa para coser' y 'hebra con la que forman las arañas, gusanos de seda, etc., sus telas y capullos' (DLE: s. v. hilo), apreciable la segunda en nuestro tratado: «[...] haze [el gusano] unas telillas o hilos de seda delgados, a manera de telas de arañas, que la naturaleza les deviera de dar para ayuda a vaciar y tirar los corezuelos que mudan» (Casas, 1581: 51r). Todo ello, soslayando otros significados del verbo y del sustantivo en los diccionarios, que por medio de metáforas y procesos semánticos de distinto tipo se han incrementado; por ejemplo, tenemos hilar como 'dicho de algunas cosas: Discurrir, trazar o inferir de otras' (DLE: s. v. hilar) o bilo como 'curso o evolución de una cosa, especialmente del discurso o del pensamiento' (DLE: s. v. hilo).

\subsection{Joyante}

\section{Contexto de Uso del tratado}

«La manera de hilar esta seda se divide en dos o tres maneras: en redonda o joyante, que la una es gorda y la otra delgada, y la delgada buena para aparejos. Y en esta ay otras diferencias conforme al gordor o delgadez d'ella, porque una será buena para telas, otra para tramas, otra para pelos. Y en la gorda no ay diferencia ninguna, porque d'ella se haze el capillejo, que es la seda torcida o floxos» (Casas, 1581: 73v).

TESTIMONIOS TEMPRANOS DEL VOCABLO (CON SENTIDO AFÍN AL USO DEL TRATADo)

«Porque somos informados que la seda joyante que se haze en el reyno de Granada y Almería, de algunos años a esta parte, se va estragando porque se ha traýdo y metido en el dicho reyno simiente y moreras de Mecina, y del reyno de Murcia, y Valencia, y de otras partes donde la seda no es tan buena, mandamos que no se traygan ni metan de fuera del dicho reyno de Granada y Almería moreras algunas, ni se planten » (1523-1551, anónimo: Repertorio de todas las premáticas y capitulos de cortes; CORDE).

«En esta Mixteca hay muchas provincias y pueblos, y aunque es tierra de muchas montañas y sierras, va toda poblada. Hace algunas vegas y valles; pero no hay vega en toda ella tan ancha que pase de una legua. Es tierra muy poblada y rica, adonde hay minas de oro y plata, y muchos y muy buenos morales, por lo cual se comenzó a criar aquí primero la seda; y aunque en esta Nueva España no ha mucho que esta granjería se comenzó, se dice que se cogerán en este año más de quince mil libras de seda; y sale tan buena, que dicen los maestros que la tratan, que la tonozti es mejor que la joyante de Granada; y la joyante de esta Nueva España es muy extremada de buena seda » (1536-1541, Motolinía [fray Toribio de Benavente]: Historia de los Indios de la Nueva España; CORDE).

Tabla 4. Un contexto de uso de joyante en el Arte para criar seda y contextos de uso complementarios 
Ya a propósito de capillejo pude decir algo de esta otra voz, por la implicación en la preparación de esa cierta clase de madeja de la seda redonda, que se contrapone en las líneas elegidas del tratado para la Tab. 4 - las mismas de la Tab. 2-a la joyante. El fragmento puntualiza que la seda joyante se define por su delgadez, frente al grosor de la redonda, de la que trataré más abajo. La presente deja sus primeras apariciones, según el $D E C H(s . v$. joya), en 1590 , fecha que es factible adelantar no solo por el propio Arte para criar seda, sino por las otras dos citas de la Tab. 4. Además, desde los primeros usos revela un patente cariz técnico, que se traduce en su presencia, con el sentido esbozado, en algunos de los diccionarios de los siglos XVI y XVII, como son Franciosini (1620: s. v. joyante seda) —'seta della più fine e lustrante'- $\mathrm{o}$, con una definición muy próxima, Covarrubias (1611: s. v. joya) —'la muy fina y lustrosa'-. También, después, Aut. (s. v. joyante): '[...] se aplica y dice de la seda muy fina y de mucho lustre. [...] Los passamanos que se hovieren de hacer para calzas y guarniciones de vestidos y otros efectos han de ser todos de seda joyante'. Estos diccionarios llegan a incidir en contextos de uso distintos para la voz: 'pólvora joyante, la muy refinada' (Covarrubias, 1611:s. v. joya).

Es la última una muestra de la productividad de la solución morfológica, pues el adjetivo en cuestión se ha explotado en sentidos adicionales al propio de la actividad sedera. Influye la transparente conexión con joya, de la cual deriva gracias a la adjunción del sufijo -nte, el cual, aunque suele operar sobre bases verbales, también actúa sobre las nominales ${ }^{31}$. Así, joyante ha tenido cabida en contextos donde su función es describir el preciosismo de la entidad calificada, tal como manifiestan escritores de la talla de Valle-Inclán ${ }^{32} \mathrm{o}$ Gabriel Miró ${ }^{33}$, cultivadores de una prosa, por momentos, altamente estetizante, como es bien conocido (Tollinchi, 2004: 365).

31 Una derivación análoga es la siguiente: comedia > comediante. Se trata de un ejemplo que se aduce, junto a las explicaciones pertinentes, en la $\operatorname{NGLE}(\$ 6.10 \mathrm{~d})$.

$32 \mathrm{Al}$ menos, en una ocasión: «La clara luz de la tarde madrileña entraba por los balcones reales, y el séquito joyante de tornasoles, plumas, mantos y entorchados, evocaba las luces de la Corte de Carlos IV» (1927-1931, Valle-Inclán, Ramón María: La corte de los milagros; CORDE). Se ha llegado a incluir este derivado en un grupo de «neologismos valleinclanianos» (García Gallarín, 1998: 8).

$33 \mathrm{Al}$ menos, dos veces en la misma obra; señalo solo un ejemplo: «Cuando los dos primos salieron, ya estaba el cielo limpio, joyante, de un azul nuevecito y húmedo, como el verdor de los árboles que goteaban la lluvia pasada y retenida» (1910-1926, Miró, Gabriel: Las cerezas del cementerio; CORDE). Y una vez más en El obispo leproso, ahora en alusión a la seda: «Sus vestiduras pesan tres mil libras de capullo-almendra, del que se hila la seda joyante, escaldada por devotos terciopelistas de la comarca que trabajan cantando» (Miró, 1974: 329). 


\subsection{Madexa}

\section{Contexto de USO Del TRATAdo}

«Iten, se á de procurar que la seda vaya bien cruzada en la madexa, que en esto suele aver descuido, por donde del todo se pierde. Assí mesmo, que vaya con buelta, porque si no la lleva, la hebra queda ancha y no van pegadas unas a otras, lo cual es gran fealdad y es perdición de seda » (Casas, 1581: 75r).

TESTIMONIOS TEMPRANOS DEL VOCABLO (CON SENTIDO AFÍN AL USO DEL TRATADO)

«Esto es por fazannya que mataron la fija de Ferrando de Sancto Domingo cómmo dizían que la matara don Ferrando \& su hermanna. Et leuáronle todo lo que tenýa en casa, et vna muger dixo que tenýa tres madexas de aquella muger que mataran et robaran, \& que las enpennara aquella muger, que mataran por dineros» (a. 1284, anónimo: Libro de los fueros de Castiella; CORDE ${ }^{34}$ ).

«Orfreses nin cintas nin cuerdas nin cannudos doro nin de argent nin madexas doro nin de argent nin de lino nin de cannamo nin ningun filado njn seda nin cadarço nin algodon non dan peaie» (ca. 1295, anónimo: Aranceles de aduanas en Cantabria; CORDE).

Tabla 5. Un contexto de uso de madexa en el Arte para criar seda y contextos de uso complementarios

Frente a capillejo, en los términos antes bosquejados, madexa apunta a una disposición del hilo de carácter general, al no utilizarse en exclusiva dentro del ámbito sedero. Lo ejemplifica esta ocurrencia, donde se relaciona con el algodón:

[...] e luego tras esta gente salió toda la gente, ministros de los que sirvie a los ídolos, vestidos con ciertas vestimentas, algunas cerradas por delante como capuces e los brazos fuera de las vestiduras, e muchas madejas de algodón hilado por orla de las dichas vestiduras, e otros vestidos de otras maneras ( $p .1525$, Tapia, Andrés de: Relación hecha por el señor Andrés de Tapia, sobre la conquista de México; CORDE).

Dicho contexto debe sumarse al del Arte para criar seda y los dos complementarios de la Tab. 5, pues de todos se infieren datos importantes para la semántica de la voz. En general, la madeja requiere que el hilo se enrede con un orden, pauta importante para proseguir con las labores textiles, como ocurría con el capillejo. Pero llevarlo a cabo, como advierte De las Casas, entraña no pocos riesgos, puesto que, por ejemplo, la hebra, o el hilo, puede quedar con holgura, «lo cual es gran fealdad y es perdición de seda », como recoge el contexto aducido del

34 No reproduzco la siguiente ocurrencia del corpus, según la cronología: es un pasaje equivalente, con cambios en las grafías (1290-1300, anónimo: Fuero Burgos. Philadelphia Ems.245; CORDE). 
tratado. Igualmente, la seda debe ir bien «cruzada en la madexa», como señala el mismo extracto de la Tab. 5, es decir, ha de estar convenientemente trabada. Para ello, en la época, y hasta la actualidad, se ha utilizado una herramienta que recibe el nombre de aspa, ya definida en Covarrubias (1611: s. v. aspa): 'el aspa de que usan la mugeres para obrar el hilado y ponerlo en madejas se dixo así, porque van atravessando el hilo de una parte a otra, y esto llaman aspar'. Existe, de hecho, una familia léxica interesante en torno a este proceso, que no solo involucra a aspa y aspar; también existe un adjetivo participial, aspada: «Y que fuesen obligadas a las traer en madexas aspadas» (1491-1516, Santa Cruz, Alonso de: Crónica de los Reyes Católicos; CORDE). No disuena, así las cosas, la definición que da del término en cuestión Covarrubias (1611: s. v. madexa): 'el hilo aspado que queda en círculo para devanarse y pulirse'. Tanto aspa como aspar están en el $D L E$ con alusión a estos valores, entre otros, lo cual marca su continuidad a lo largo de los siglos, con sentidos que, como se extrae de lo expuesto, no se limitan a la seda. Por ejemplo, puede ponerse en relación con las ovejas y la lana:

Herminia explicaba el intrincado proceso de convertir en chaqueta la peluca de oveja [...]. Explica que después de la trasquilada, «hay que escaldar la lana con agua hirviendo y lavarla». Una vez seca y limpia, «se despeluza. Después se carda, se hace el copo y se hila».

«De ahí va a la mazorca. Se aspa y de la madeja va a la devanadera donde se hace ovillo. Y de ahí al telar, que es cuando sale la estameña (Jiménez, 2017).

La etimología, en vista de este significado de la voz, es sumamente elocuente, la cual es explicitada en el $D E C H$ (s. v. madeja): «[...] del lat. MATAXA 'hilo', 'seda cruzada', que en romance ha tomado en todas partes el mismo sentido que en castellano». En este diccionario se atribuye al Libro de buen amor su datación más temprana —en 1330 y 1343, en virtud de la hipótesis de las dos redacciones (DECH: I, LXI) - , pero se puede adelantar, según los ejemplos de la Tab. 5, al siglo XIII.

Por su parte, para la madexa de pequeño tamaño De las Casas recurre a la forma madexuela en una ocasión: «Si muerto el gusano le quitan esta ternilla y la secan, se buelve dura, y cogida a manera de una madexuela se verá deshazer d'ella hebras de seda que allí están cogidas» (Casas, 1581: 35v). Esta solución tiene cierta presencia en los diccionarios del español, aunque en ocasiones como equivalente de alguna análoga; es el caso de Oudin (1607: s. v. madexita o madexuela) - 'petit escheveau ${ }^{35}$ - o Franciosini (1620: s. v. madexita, madexuela) —'matassina, ma-

35 Hoy, écheveau 'madeja'. 
tassetta'- También figura en Salvá (1846: s. v. madejuela) o en Alemany y Bolufer (1917: s. v. madejuela). Para terminar, mientras que la voz madexa es definida en los repertorios más recientes del español, madexuela, pese a que está aún en el $D R A E$ 1984 (s. v. madejuela $)^{36}$, ya no se recoge en el $D E A$ ni en el $D L E$, donde sí se encuentra la forma no derivada.

\subsection{Redondo}

\section{CONTEXTO DE USO DEL TRATADO}

«La manera de hilar esta seda se divide en dos o tres maneras: en redonda o joyante, que la una es gorda y la otra delgada, y la delgada buena para aparejos. $\mathrm{Y}$ en esta ay otras diferencias conforme al gordor o delgadez d'ella, porque una será buena para telas, otra para tramas, otra para pelos. Y en la gorda no ay diferencia ninguna, porque d'ella se haze el capillejo, que es la seda torcida o floxos» (Casas, 1581: 73v).

\section{\begin{tabular}{l|l} 
TESTIMONIOS TEMPRANOS DEL & TESTIMONIOS TEMPRANOS DEL VOCABLO
\end{tabular}} VOCABLO CON SENTIDO AFÍN AL USO DEL TRATADO

«[...] e sobre Alcocer mio Cid iva posar, / en «otrosy, el arienço de la otra seda redonda, a tres maraun otero redondo, fuerte e grand; / acerca vedís. iii» (1462, anónimo: Arancel de precios y salarios corre Salón, agua no.l' puedent vedar» (ca. de Cuenca [Documentos sobre industria textil]; CORDE). 1140, anónimo: Poema de Mio Cid; COR$D E)$.

«[...] acordaren ellos con el parecer de la madre de la cassa e sus discretas, y la cassa haga su tunba e dos doseres para $\ll[\ldots]$ que uno omne es nacido de carne / que es senior de todo el mundo, / así cumo el cilo es redondo / de todas gentes senior será / i todo seglo iugará» (ca. 1180, anónimo: Auto de los Reyes Magos; $\mathrm{CDH}$ ).

echar ençima, uno de paño negro con sus flocaduras de seda negra a la Redonda para los días cotidianos y el otro de terçiopelo negro forrado en bocaçin con sus flocaduras de seda a la Redonda, y en este doser estén bordados unos escudos de mys armas de mendoça e de luna » (1534, anónimo: Testamento D. ${ }^{a}$ Brianda; $\left.C D H\right)$.

Tabla 6. Un contexto de uso de redondo en el Arte para criar seda y contextos de uso complementarios

A partir de capillejo y joyante, ya he podido pronunciarme, de modo somero, sobre el sentido de redondo en el ámbito especializado de la sericicultura, que es la orientación que asume en el pasaje del Arte para criar seda de la Tab. 6, igualmente presente en la Tab. 2 y en la 4 . En este se asocia, en particular, a un tipo de seda gruesa o, como dice De las Casas, «gorda», a diferencia de la joyante, «delgada», también en los términos de nuestro autor. La de mayor calidad es la joyante, lo cual explica que deban deslindarse una y otra para ser utilizadas según sus posibilidades. Por ejemplo, siguiendo con el fragmento del tratado, la redonda sirve, de manera especial, para el capillejo, como ya he expuesto con anterioridad

36 Cito el $D R A E-1984$ por la edición del diccionario accesible en el NTLLE. 
y refrenda, dos siglos más tarde, Elgueta y Vigil al definir la seda redonda como 'la que se hila del ocal, y es la más basta, gruesa y ordinaria, y sirve para sedas de coser, floxas, capillejos, tramas y para galones' (1761: 172). Pero, más aún, tanto en lo que respecta a joyante como a redondo tenemos un párrafo significativo en el Arte para criar seda que sigue al último mencionado:

Consiste el hilarse gorda echar muchos capullos en la caçuela y en delgada echar pocos, y teniendo este respeto a la bondad y fortaleza del capullo, que con iguales capullos una podrá ser más gorda o delgada que otra. En esto ay que dar un aviso, que es que el que tuviere flaco capullo no procure hazer seda gorda ni redonda, porque desperdiciará mucha seda, sino delgada para aparejos conforme a la maña que el hilador se diere. Y el que tuviere buen capullo fuerte puede hilar como quisiere, gorda o delgada (Casas, 1581: 73v-74r).

Es decir, con la seda redonda podrán obtenerse hilos más gruesos que con la joyante, y, en general, se recomienda que se tomen más capullos si se busca obtener hilos de cierto volumen, frente a la preparación del hilado fino, para el cual los capullos deben ser menos y la seda joyante resulta idónea. Además, con los capullos menos densos, según el último fragmento, es mejor evitar «hazer seda gorda ni redonda, porque desperdiciará mucha seda »; habría que destinarlos al hilado fino.

La seda redonda, en consecuencia, se caracteriza por su firmeza, propiedad en la que suelen insistir los diccionarios, pero, no extrañamente, recurriendo a un intermediario léxico. Veámoslo a través de Alemany y Bolufer (1917). Si en este acudimos a la voz redondo, daremos con una precisión que puede seguir resultando oscura, ya que continúa siendo especializada: 'seda ocal' (Alemany y Bolufer, 1917: s. v. redondo). Pero la remisión acaba dándonos un resultado, pues el repertorio en cuestión explica seda ocal como 'la de inferior calidad pero fuerte, que se saca del capullo ocal' (Alemany y Bolufer, 1917: s. v. seda). Por último, capullo ocal no debe generarnos problemas en su sentido pese a su carácter técnico, una vez que lo he considerado antes, a propósito de hilar.

De esta forma, una significación especializada de una palabra se suma a otras generales en la misma lengua, sobre todo con los valores de 'de forma circular o semejante a ella' y 'de forma esférica o semejante a ella' (DLE: s. v. redondo), conformando las tres, y otras, facetas de una palabra polisémica cuya etimología admite poca duda: «[...] del lat. ROTŬNDUS» (DECH: s. v. redondo). Llega el $D E C H$ a situar su primer uso en el año 1020, en consonancia con Oelschläger (1940: s. v. redondo), así como acude a los versos del Poema de mio Cid de la Tab. 6 (DECH: s. v. redondo). Desde los sentidos generales, el adjetivo pasará a 
designar la mentada clase de seda por el grosor de esta, frente a la joyante, con las propiedades que ya he planteado.

\subsection{Seda}

\begin{tabular}{|c|}
\hline CONTEXTO de uso del TRATAdo \\
\hline $\begin{array}{l}\text { «Procopio, auctor griego, dize que dos monges truxeron esta semilla de seda de la India Oriental, de una } \\
\text { ciudad que se llama Serinda, a la ciudad de Constantinopla en tiempo del emperador Justiniano, que } \\
\text { imperó el año del nacimiento de nuestro señor Jesucristo de quinientos y veinte y ocho, e imperó treinta } \\
\text { y ocho años» (Casas, 1581: 1r-1v). }\end{array}$ \\
\hline TESTIMONIOS TEMPRANOS DEL VOCABLO (CON SENTIDO AFíN AL USO DEL TRATADO) \\
\hline $\begin{array}{l}\text { «Priso Pharaon la sortija de oro que avie en su mano e diola a Josep e vistiol pannos de seda e metiol oral } \\
\text { de oro sobre so cuello e fizol seer sobre la syella que era apres de la suya, e fizol obedecer por toda tierra de } \\
\text { Egipto e pusol nonbre a Josep Çaph[nat] Pane(l)a, e diol por mugier ad Acenat fija de Furtifar, princep } \\
\text { d'On» (ca. 1200, Almerich: La fazienda de Ultra Mar; CORDE). }\end{array}$ \\
\hline $\begin{array}{l}\text { «Unqua calçaba otras çapatas, / sino de cordobán entretalladas, / pintadas eran con oro e con plata, / } \\
\text { cuerdas de seda con que las ata» (ca. 1215, anónimo: Vida de Santa María Egipcíaca; CORDE). }\end{array}$ \\
\hline
\end{tabular}

Tabla 7. Un contexto de uso de seda en el Arte para criar seda y contextos de uso complementarios

El nuevo fragmento del Arte para criar seda, además de ilustrar el uso lingüístico de la voz, suscita un notable interés cultural, pues remite a una hipótesis acerca de cómo llegó a Occidente esta fibra natural, que se relaciona con otra voz importante, semilla, la cual abordaré tras esta. Este contexto debe reforzarse con los dos externos recogidos en la última tabla, donde se mencionan «pannos de seda $\gg$ y «cuerdas de seda ». Evidencian ambos las múltiples posibilidades de esta materia, una vez que ha sido convenientemente tratada, como pudiera ocurrir con el algodón o la lana, pero en este caso con un genuino lustre propiciado, en parte, por su singular origen, en el cual insiste Covarrubias (1611:s. v. seda): 'es nombre genérico a muchas maneras de telas echas de seda. Es la seda una hebra delgada y sutil que se hila de los capullos de los gusanos que llamamos de seda, pero este nombre se le dieron los seres, pueblos de la Scitia, cerca de los cuales se crían unos árboles que no solo dan hoja, pero también una especie de lana muy delgada y suave de que haze mención'.

Una etimología convincente se postula en el $D E C H($ s. v. seda): «[...] probablemente del lat. SAETA 'cerda de puerco, de caballo, etc.,' 'sedal de pescar', que en la Edad Media debió de aplicarse al hilo de seda, según se deduce de las lenguas romances». En efecto, en la historia del español la palabra no ha operado en ex- 
clusiva en el ámbito sericícola, sino que, entre otras cosas, ha denominado la 'cerda de algunos animales, especialmente del jabalí' (DLE: s. v. seda), de donde, por un proceso metafórico, dada la semejante apariencia que se puede intuir entre la cerda - en el sentido de 'pelo de algunos animales, como el jabalí, cerdo, etc., que es corto y recio' (DLE: s. v. cerda) - y la sustancia que segrega el gusano, acabó designando a esta, aunque no en exclusiva dentro del mismo filo: 'líquido viscoso segregado por ciertas glándulas de algunos artrópodos, como las orugas y las arañas, que sale del cuerpo por orificios muy pequeños y se solidifica en contacto con el aire formando hilos finísimos y flexibles' (DLE: s. v. seda). Finalmente, es llamativo que el $D E A$ no contemple entre las acepciones de seda ninguna referencia a la cerda, lo cual evidencia una especialización respecto al gusano de seda y otros artrópodos. Sí que, tempranamente, aludía a este sentido Nebrija (1495: s. $v$. seda como de puerco $)^{37}$. Cabe preguntarse si en estas interferencias semánticas entre seda y cerda juega algún papel la fonética, en virtud de su similitud en este plano, más aún en contextos seseantes.

\subsection{Semilla}

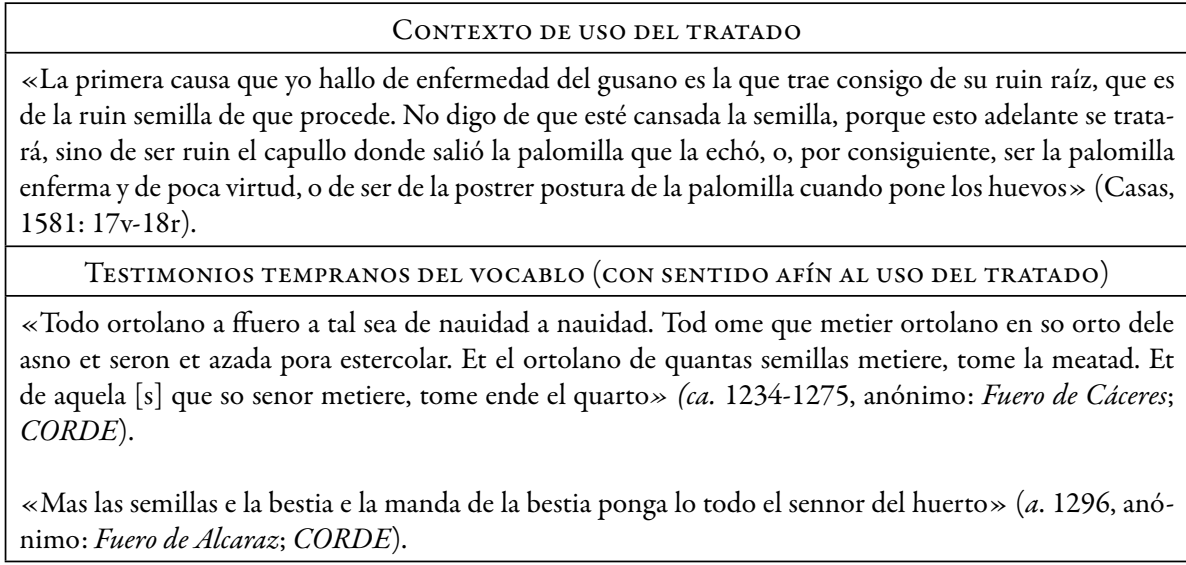

Tabla 8. Un contexto de uso de semilla en el Arte para criar seda y contextos de uso complementarios

Como he podido adelantar, la presente voz aparece ligada a seda en numerosos contextos del tratado, y varios de ellos podrían guiarnos de cara a nuestra incursión

37 Cito a Nebrija (1495) por la edición del diccionario accesible en el NTLLE. 
en su semántica. Pero, al respecto, he elegido unas líneas en que se imputa al mal estado del capullo un perjuicio para la mariposa que sale de él, que a su vez podría transmitir a sus huevos, origen de una posible «enfermedad del gusano de seda», nacido así de una «ruin raíz» o una «ruin semilla». Es decir semilla alude en nuestro contexto, al huevo del que procede el gusano de seda y, por su parte, se aprehende como matriz para la seda, lo cual explica la continuidad del sintagma semilla de seda en el texto, presente, entre otros lugares, en el uso de De las Casas de la Tab. 7. Aúna esta palabra dos de los intereses principales de nuestro autor, que han de verse conectados: la cría del gusano de seda y la producción de la seda, dos perspectivas que se imbrican en el mencionado sintagma. Y goza semilla de tanta importancia que se desliza hasta el título completo de la editio princeps: Arte para criar seda desde que se rebive una semilla hasta sacar otra.

La voz comporta, así las cosas, una alusión al origen, principio semántico evidenciado, con implicaciones más técnicas o generales, en diversidad de diccionarios del español. Lo ejemplifica la temprana acepción de Franciosini (1620: s. v. semilla): 'seme o i granelli d'ogni sorte biada'. Repertorio lexicográfico en que se muestra otra muy apropiada a nuestros efectos: 'seme da bachi o filugelli da far seta' (Franciosini, 1620: s. v. semilla de seda). La presencia de esta última denota que la coaparición no disonaba en la época ${ }^{38}$, más allá del tratado, y permite, aún más, postular cierto arraigo en los contextos sederos.

Asimismo, semilla es resultado de una etimología que, una vez más, precisa el $D E C H$ (s.v. semilla): «[...] en el dialecto mozárabe se decía xeminio, es probable que se tomara de este dialecto, y que ahí viniese del lat. SEMĬNĬA, plural de SEMǏNIUMM». Palabra, por tanto, ya orientada semánticamente hacia el origen de los objetos desde la lengua latina, con especial interés hacia las plantas, que es el valor que asumen cuatro de las cinco acepciones que en la actualidad le asigna el $D L E$ (s. v. semilla): la primera, 'parte del fruto de las fanerógamas, que contiene el embrión de una futura planta, protegido por una testa, derivada de los tegumentos del primordio seminal'; la segunda, 'grano que en diversas formas produce las plantas y que al caer o ser sembrado produce nuevas plantas de la misma especie'; la tercera, 'fragmento de vegetal provisto de yemas, como tubérculos, bulbos, etc.', y la quinta, 'granos que se siembran, exceptuados el trigo y la cebada'. Me queda por citar la cuarta, general: 'cosa que es causa u origen de que proceden otras'.

38 Como lo sugiere, de igual forma, el siguiente ejemplo: «Antes que esta carta se escribiese en este año de 1541, anduve por esta tierra que digo, más de treinta días; y por el mes de Enero ví en muchas partes semilla de seda, una que revivía, y gusanicos negros y otros blancos, de una dormida, y de dos, y de tres, y de cuatro dormidas: y otros gusanos grandes fuera de las panelas, en zarzos» (15361541, Motolinía [fray Toribio de Benavente]: Historia de los Indios de la Nueva España; CORDE). 
Por último, cabe mencionar que, como dice el $D E C H$ (s. v. semilla), esta es una «palabra tardía, que no sustituye a simiente hasta el siglo XVII». Ello explica la mayor facilidad de documentar simiente hasta dicha fecha, en detrimento de semilla, mientras que en nuestro tratado esta última es la preferida, con más de un centenar de apariciones, frente a las solo tres de simiente: «[...] digo por sucessión de simiente y generación de macho y hembra» (Casas, 1581:1v), «[...] porque unos nacen y se crían tan solamente de simiente» (Casas, 1581:5r) y «[...] proceder por generación y simiente de macho y hembra» (Casas, 1581: 96r).

\section{Conclusiones}

Las ocho voces estudiadas evidencian el interés léxico del Artepara criar seda, particularmente el referente a la fibra natural que figura en su título. Para escudriñar el campo semántico que pivota a su alrededor, he partido del tratado a fin de profundizar en estas, rastreándolas en la historia del español. Las ocho, con su trayectoria singular dentro de la lengua, revelan diferentes tendencias que emanan de un autor que incentiva su consolidación, cuando no la de ciertas facetas semánticas suyas. Voces como joyante — por su sentido técnico - o semilla — por su rivalidad con simiente - reciben ese impulso general, mientras que otras - atanquia, capillejo y redondo- despliegan una vertiente semántica que no es la más fácil de documentar en sus primeros pasos dentro del español. Asimismo, otras más extendidas antes y después de la aparición del tratado son citadas, algunas propias de la sericicultura - seda - y otras no exclusivas de esta materia entre las labores textiles — hilar y madexa-. De las ocho, solo es difícil asegurar la pervivencia en el español de hoy, al menos de forma amplia, de atanquia y capillejo; de las demás, diversos indicios apuntan a lo contrario, con distintos grados de frecuencia. Pero en el Arte para criar seda todas forman parte de unas valiosas explicaciones técnicas, vehiculadas por medio de una expresión lingüística que no lo es menos.

\section{BibLIOgR A Fía}

BARCeló, Carmen, y Ana Labarta (2001): «Árabe y español: un contacto multisecular», en Julio Calvo Pérez (ed.), Contacto interlingüistico e intercultural en el mundo hispano, Valencia, Instituto Valenciano de Lenguas y Culturas Amerindias/Departament de Teoria dels Llenguatges, Universitat de València, vol. I, pp. 31-52.

Carrillo Cázares, Alberto (2003): «Crítica textual. Los manuscritos originales: características, diferencias, orden», en fray Guillermo de Santa María, 
Guerra de los chichimecas (México 1575-Zirosto 1580), ed. Alberto Carrillo Cázares, 2. ${ }^{a}$ ed., Zamora, El Colegio de Michoacán/Universidad de Guadalajara/El Colegio de San Luis, pp. 59-80.

Casas, Gonzalo de las (1581): Arte para criar seda, Granada, René Rabut.

$C D H=$ Real Academia Española: Corpus del nuevo diccionario histórico del español. En línea: <http://web.frl.es/CNDHE/view/inicioExterno.view> [04/06/2020].

Comisión Española de la Ruta de la Seda (1996): España y Portugal en las rutas de la seda. Diez siglos de producción y comercio entre Oriente y Occidente, Barcelona, Universitat Autònoma de Barcelona.

CORDE = Real ACADEmia Española: Corpus diacrónico del español. En línea: <http://corpus.rae.es/cordenet.html> [04/06/2020].

Cormon, G. L. B, y Vincenzo Manni (1821): Dizionario italiano-spagnuolo e spagnuolo-italiano, Lyon, B. Cormon e Blanc.

Coseriu, Eugenio (1981): «Introducción al estudio estructural del léxico», en Principios de semántica estructural, 2. ${ }^{a}$ ed., Madrid, Gredos, pp. 87-142.

DAVAI = CORRIENTE, Federico (1999): Diccionario de arabismos $y$ voces afines en iberorromance, Madrid, Gredos.

$D E A=$ Seco, Manuel, Olimpia Andrés y Gabino Ramos (2011): Diccionario del español actual, 2. ${ }^{\text {e }}$ ed., Madrid, Aguilar.

DECH = Corominas, Joan, y José Antonio Pascual (1980-1991): Diccionario crítico etimológico castellano e hispánico, 6 vols., Madrid, Gredos.

DHLE = Real ACAdemia Española (1933-1936): Diccionario histórico de la lengua española, Madrid, Imprenta de Librería y Casa Editorial Hernando. En línea: <http://web.frl.es/DH1936.html> [04/06/2020].

$D L E=$ Real ACADEMIa ESPaÑola y AsociaCión DE ACADEMIAS DE LA LeNGUA EsPaÑola: Diccionario de la lengua española. En línea: <https://dle.rae. es> [04/06/2020].

Dubroca, Jean-François (1826): Conversaciones de un padre con sus hijos sobre la historia natural, t. IV, trad. Manuel de Ascargorta y Ramírez, 3. ${ }^{a}$ ed., Madrid, Imprenta que fue de Fuentenebro.

Elgueta y Vigil, Antonio (1761): Cartilla de la agricultura de moreras y arte para la cría de la seda, Madrid, Gabriel Ramírez.

Franch Benavent, Ricardo, y Germán Navarro Espinach (coords.) (2017): Las rutas de la seda en la historia de España y Portugal, Valencia, Universitat de València.

García Gallarín, Consuelo (1998): Léxico del 98, Madrid, Editorial Complutense. 
García Herrero, M. ${ }^{a}$ del Carmen (2008): «Actividades laborales femeninas a finales de la Edad Media: registros iconográficos», en María del Carmen Lacarra Ducay (coord.), Arte y vida cotidiana en época medieval, Zaragoza, Institución «Fernando el Católico»,pp. 17-48.

Garrido Aranda, Antonio (1996): «Estudio preliminar» a Gonzalo de las Casas, Arte nuevo para criar seda, ed. Antonio Garrido Aranda, Granada, Universidad de Granada, pp. XIII-XXXVII.

GonZÁlez Obregón, Luis (1903): «Guerra de los chichimecas, por Gil González D’Ávila», Anales del Museo Nacional de México, segunda época, 1, pp. 159-171 y $185-194$.

GonZÁlez Sopeña, Inmaculada (2019): Los arabismos del reino de Granada a través de la documentación archivistica (finales del siglo XV-siglo XVII), Tesis doctoral inédita, Universidad de Granada.

Gutiérrez Rodilla, Bertha M. (1998): La ciencia empieza en la palabra. Análisis e historia del lenguaje cientifico, Barcelona, Ediciones Península.

JimÉNEZ, Juanjo (2017): «200 ovejas salen trasquiladas de Caideros de Gáldar», La Provincia-Diario de Las Palmas, 31 de mayo. En línea: <https://www. laprovincia.es/canarias/2017/05/31/200-ovejas-salen-trasquiladas-caideros/944508.html> [04/06/2020].

JimÉNEZ Ríos, Enrique (2018): «La presentación del léxico denominador de herramientas en textos científico-técnicos (siglos XVI y XVII) en el marco de las tradiciones discursivas», Nueva Revista de Filología Hispánica, 66, 2, pp. 493-528.

López Quero, Salvador (2010): «Los arabismos del léxico médico-farmacológico del Cancionero de Baena», Nueva Revista de Filología Hispánica, 58, 2, pp. 563-582.

LORA Serrano, Gloria (1991): «La organización de la defensa militar de un estado señorial y el potencial bélico de un noble a mediados del siglo XV », Historia. Instituciones. Documentos, 18, pp. 297-338.

Maíllo SAlgado, Felipe (1998): Los arabismos del castellano en la Baja Edad Media. Consideraciones históricas y filológicas, 2. ${ }^{\text {a }}$ ed., Salamanca, Universidad de Salamanca.

MARín López, Rafael (2008): Documentos para la historia de la seda en el reino de Granada (siglos XV-XVIII), Granada, Universidad de Granada.

Mármol Ávila, Pedro (2020): «Acercamiento a un proceso en marcha: la edición crítica del Arte para criar seda (1581), de Gonzalo de las Casas», en Carlos Mata Induráin y Miren Usunáriz Iribertegui (eds.), «Melior auro». Actas del IX Congreso Internacional Jóvenes Investigadores Siglo de Oro (JISO 2019), Pamplona, Universidad de Navarra, pp. 219-231. 
Miró, Gabriel (1974): Nuestro padre San Daniel. El Obispo leproso, 2. ${ }^{\text {e }}$ d., Madrid, Alianza Editorial.

MuÑoz GARrigós, José (1979): «El vocabulario de la seda en el dialecto murciano (Semasiología y Onomasiología)», Murgetana, 55, pp. 5-46.

$N G L E=$ Real ACADEmia Española y Asociación DE ACADEmias de la Lengua Española (2009): Nueva gramática de la lengua española, Madrid, Espasa.

NTLLE = Real Academia Española (2001): Nuevo tesoro lexicográfico de la lengua española, Madrid, Espasa. En línea: <http://ntlle.rae.es/ntlle/SrvltGUILoginNtlle> [04/06/2020].

Oelschläger, Victor R. B. (1940): A Medieval Spanish Word-List. A Preliminary Dated Vocabulary of First Appearances up to Berceo, Madison, University of Wisconsin Press.

PCG = Menéndez Pidal, Ramón, con la colaboración de Antonio G. Solalinde, Manuel Muñoz Cortés y José Gómez PÉrez (eds.) (1955): Primera Crónica General de España que mandó componer Alfonso el Sabio y se continuaba bajo Sancho IV en 1289, t. I, 2. ${ }^{\text {e }}$., Madrid, Seminario Menéndez Pidal/Gredos.

Pottier, Bernard (1981): «Lexique Médiéval Hispanique», Cabiers de Linguistique Hispanique Médiévale, 6, pp. 179-217.

Quirós García, Mariano (2015): «El Libro de Agricultura de Gabriel Alonso de Herrera: un texto en busca de edición », Criticón, 123, pp. 105-131.

Quirós García, Mariano (2017): «El Libro de agricultura de Gabriel Alonso de Herrera en el Diccionario de Autoridades, o de la en ocasiones complicada relación entre filología y lexicografía », Revista de Investigación Lingüistica, 20, pp. 131-156.

Salvá, Miguel, y Pedro Sainz de Baranda (1849): Colección de documentos inéditos para la historia de España, t. Xv, Madrid, Viuda de Calero.

Serrano-Niza, Dolores (2007): «Arabismos relacionados con el léxico de la seda $\gg$, Revista de Filología, 25, pp. 559-566.

Sousa Congosto, Francisco de (2007): Introducción a la historia de la indumentaria en España, Madrid, Istmo.

Tollinchi, Esteban (2004): Los trabajos de la belleza modernista. 1848-1945..., San Juan, Universidad de Puerto Rico.

VAlera Escobar, Ginés (2020): «La curiosa historia del mosaico de la Virgen del Mar», La Vanguardia, 2 de julio. En línea: <https://www.lavanguardia. $\mathrm{com} /$ participacion/las-fotos-de-los-lectores/20200702/482045278091/curiosa-historia-mosaico-virgen-mar-almeria-manto-gusanos-seda-hojas-morera.html> [08/07/2020]. 
Valiente Romero, Antonio (2010): La Sericultura en España y el Arte Mayor de la Seda de Écija (siglos XVII y XVIII), Tesis doctoral inédita, Universidad de Sevilla.

Verdonk, Robert A., y M.a Jesús Mancho Dugue (eds.) (2010): Aspectos de la neología en el Siglo de Oro. Lengua general y lenguajes especializados, Ámsterdam/Nueva York, Rodopi (Foro Hispánico, 41).

Fecha de recepción: 21 de julio de 2020 Fecha de aceptación: 2 de octubre de 2020 